Turk Med Stud J 2022;9(1):36-40

CASE REPORT

DOI: 10.4274/tmsj.galenos.2022.09.01.08

\title{
ADULT HEMISPHERIC PILOCYTIC ASTROCYTOMA WITH HEMORRHAGIC COMPONENTS: A CASE REPORT
}

\author{
Ömer Polat ${ }^{1}$ (D), Nisanur Ceviz ${ }^{1}$ (D), Ahmet Emir Çelen ${ }^{1}$ (D) Elif Mercan Demirtaş² (D), Barış Chousein³ (D), \\ Ahmet Tolgay Akınci ${ }^{3}$
}

${ }^{1}$ Trakya University School of Medicine, Edirne, TURKEY

${ }^{2}$ Trakya University School of Medicine, Department of Pathology, Edirne, TURKEY

${ }^{3}$ Trakya University School of Medicine, Department of Neurosurgery, Edirne, TURKEY

\section{ABSTRACT}

We aim to present a 35-year-old male patient who was operated on for a left temporoparietal pilocytic astrocytoma with hemorrhagic components. We present a 35-year-old male patient with three months of pressure in the ear, pain in the neck, and swelling in the eyes. Cranial magnetic resonance imaging revealed a consistent mass with glial tumor morphology with cystic and hemorrhagic components in the left temporoparietal region. A gross-total excision was performed, and the pathological examination was consistent with pilocytic astrocytoma. The postoperative period was uneventful, and at the 3.5-year follow-up, the patient was free of any symptoms and radiological recurrence. Adult pilocytic astrocytomas with hemorrhagic components are relatively rare tumors. A gross-total resection, along with a close follow-up, is the primary treatment modality.

Keywords: Pilocytic astrocytoma, neurosurgery, headache, hemorrhage

\section{INTRODUCTION}

Pilocytic astrocytoma (PA) is considered a grade I tumor in the World Health Organization classification, which denotes a slow-growing, non-malignant tumor and is a relatively common glioma that often presents with a cystic lesion $(1,2)$. It is most often located in the cerebellum but can occur in all parts of the central nervous system including the optic nerve, hypothalamus, cerebellum, brain stem, and spinal cord $(1,3)$. Neuroradiologically, PA mostly appears as a contrasted and well-defined mass (4).

Pilocytic astrocytoma is more common in younger age groups, and its incidence decreases with age. The 0-14 years of age range has a higher incidence than the 15-39 and 40+ years of age ranges (5). According to the statistical reports from the Central Brain Tumor Registry of the United States, men are affected slightly more frequently than women, and incidence rates are highest among white patients compared to black, American Indian/Alaska Natives, and Asian/Pacific Islanders (5). In a study with 3,084 children from the United States, the incidence was reported 8,227 per million (6).

Headache is a common symptom for PA, yet visual disturbances, high intracranial pressure, hydrocephalus, vertigo, motor, and sensory deficits, psychiatric manifestations such as personality changes or mood-related symptoms, seizures, ataxia, and speech disturbances may also occur in PA patients $(7,8)$. However, a hemorrhagic onset is rare in PA patients, with 26 adult cases of hemorrhagic pilocytic astrocytoma (HPA) having been reported so far $(9,10)$.

Address for Correspondence: Ömer Polat, Trakya University School of Medicine, Edirne, TURKEY e-mail: omerpolat1475@gmail.com

ORCID iDs of the authors: ÖP: 0000-0001-8737-1557; NC: 0000-0003-1638-0303; AEÇ: 0000-0002-4944-6201; EMD: 0000-00022537-8144; BC: 0000-0002-0289-5528; ATA: 0000-0002-9937-076X.

Received: 19.12.2021 Accepted: 02.01.2022

Cite this article as: Polat Ö, Ceviz N, Çelen AE et al. Adult hemispheric pilocytic astrocytoma with hemorrhagic components: a case report. Turk Med Stud J 2022;9(1):36-40.

Copyright@Author(s) - Available online at https://www.turkmedstudj.com/ 
The origin of the hemorrhagic component in PA is unclear and controversial. However, White et al. (11) suggested that abnormal vascularity in PA, such as thick-walled hyalinized vessels, foci of vascular endothelial hyperplasia, and thinwalled ectatic vessels, may be associated with hemorrhage. In this study, we aimed to present a 35-year-old male patient diagnosed with cerebral PA with a hemorrhagic component.

\section{CASE REPORT}

A 35-year-old male patient was admitted to the Neurosurgery Department of Trakya University School of Medicine with complaints of pressure in the ear, neck pain, and swelling in the eye. The complaints had been going on for three months. The patient was a social drinker, a non-smoker, and his medical history was unremarkable. Cranial magnetic resonance imaging (MRI) showed a mass, consistent with glial tumor morphology, in the left temporoparietal region (Figure 1) and cystic and hemorrhagic components in some places (Figure 2).
The preoperative contrast-enhanced MRI images revealed a lobule contoured mass in the left temporoparietal area, approximately $53 \times 55 \times 43 \mathrm{~mm}$ in size. The mass caused significant pressure on the occipital horn in the left lateral ventricle, resulting in a shift of approximately $1 \mathrm{~cm}$ in the midline and had peripheral diffuse vasogenic edema. It also included cystic, solid, and hemorrhagic components. After intravenous contrast agent injection, heterogeneous enhancement in the solid component and annular enhancement in the cystic component was prominent (Figure $1,2)$. Recurrence was not noticed in the patient's early and late postoperative MRI images (Figure 3, 4).

Left temporoparietal craniotomy was performed under general anesthesia. First, the dura mater was cut and opened in a semilunar shape. Then, a trajectory was planned through a dirty yellow region of the cortex using the navigation system (S7 StealthStation, Medtronic, Minneapolis, Minnesota, USA). The biopsy sample was consistent with a glial tumor.
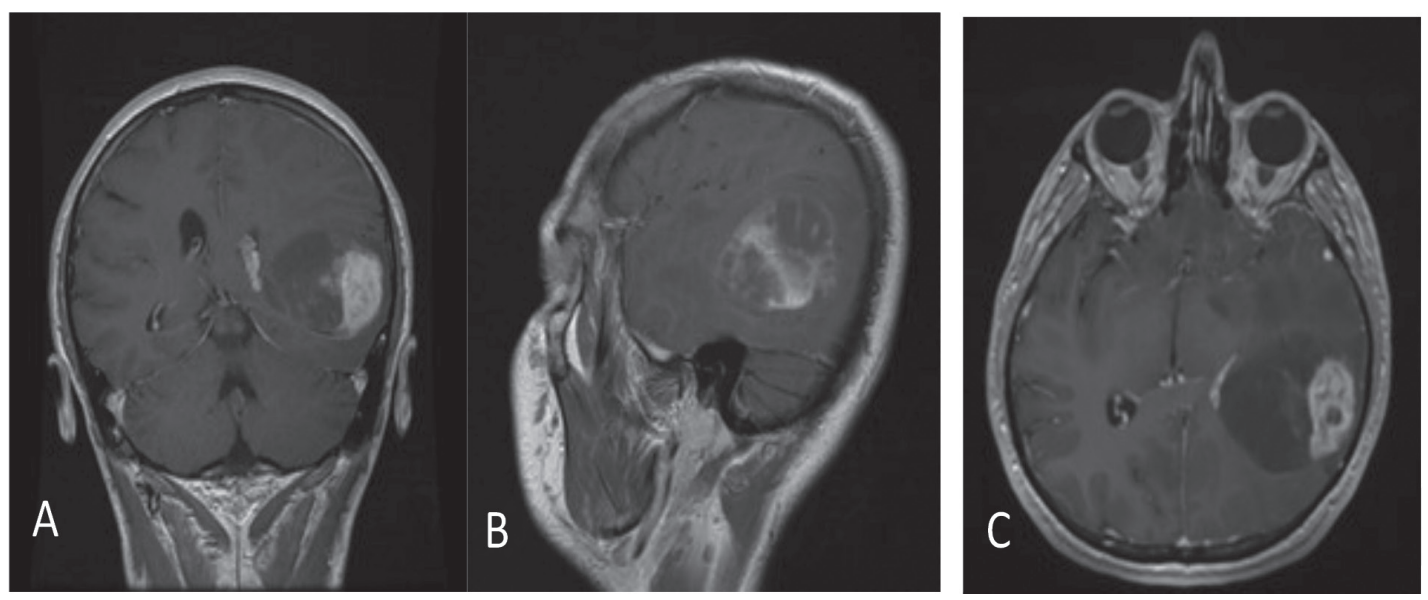

Figure 1: Preoperative contrast-enhanced T1-weighted MRI images. A: Coronal plane. B: Sagittal plane. C: Axial plane. MRI: Magnetic resonance imaging
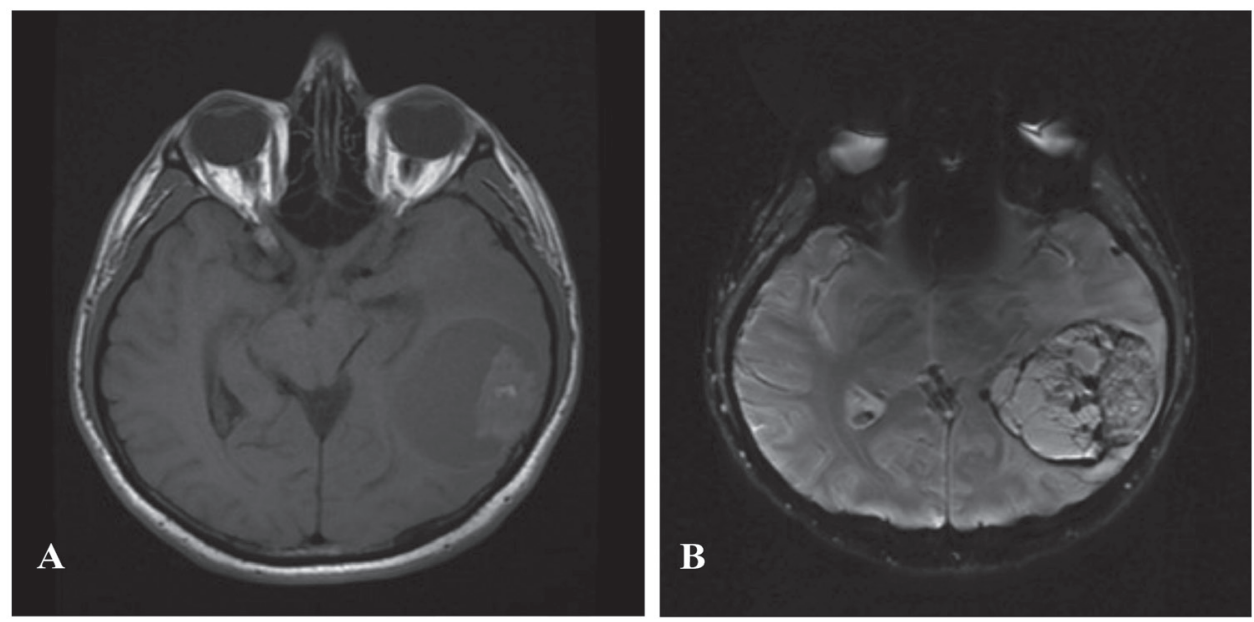

Figure 2: Preoperative axial imaging sequences. A: Non-contrast T1-weighted. B: Susceptibility weighted. 
Subsequently, the tumor was removed completely (Figure 5). The sample was examined histologically (Figure 6).

No residual tumoral residue was observed in the early postoperative MRI (Figure 3).

\section{DISCUSSION}

The presented case of PA is notable for the patient's age, supratentorial location, and hemorrhagic components.

The possibility of postoperative morbidity with radical tumor resection is low in PA (12). The prognosis of patients after surgical intervention is excellent, with a 96\% 5-year survival rate. An adjuvant radio or chemotherapy is unnecessary (13). In the 20-44 years of age group, the 5-year survival rate is $90.7 \%(5)$. The 25 -year survival rate after resection is between $50-94 \%(3)$.
Our literature search revealed that there are 26 adult patients with $\operatorname{HPA}(9,10)$. The male to female ratio was 2.1:1. Although PAs were mainly located in the cerebellum and the brainstem, HPAs were mainly located in the cerebral hemispheres, hypothalamus, suprasellar region, and cerebellum. Nine patients had HPA located in their cerebrum (10). In our patient, the tumor was located in the left temporoparietal region.

The most common symptom was a sudden headache accompanied by vomiting. Other common symptoms were vision problems, limb paresis, and seizures (10). Our patient had an unusual set of symptoms, such as pressure in the ear, pain in the nape, and swelling in the eyes. Rosenthal fibers allow us to separate these tumors from other astrocytic gliomas (14). In our case, Rosenthal fibers were also observed (Figure 6).

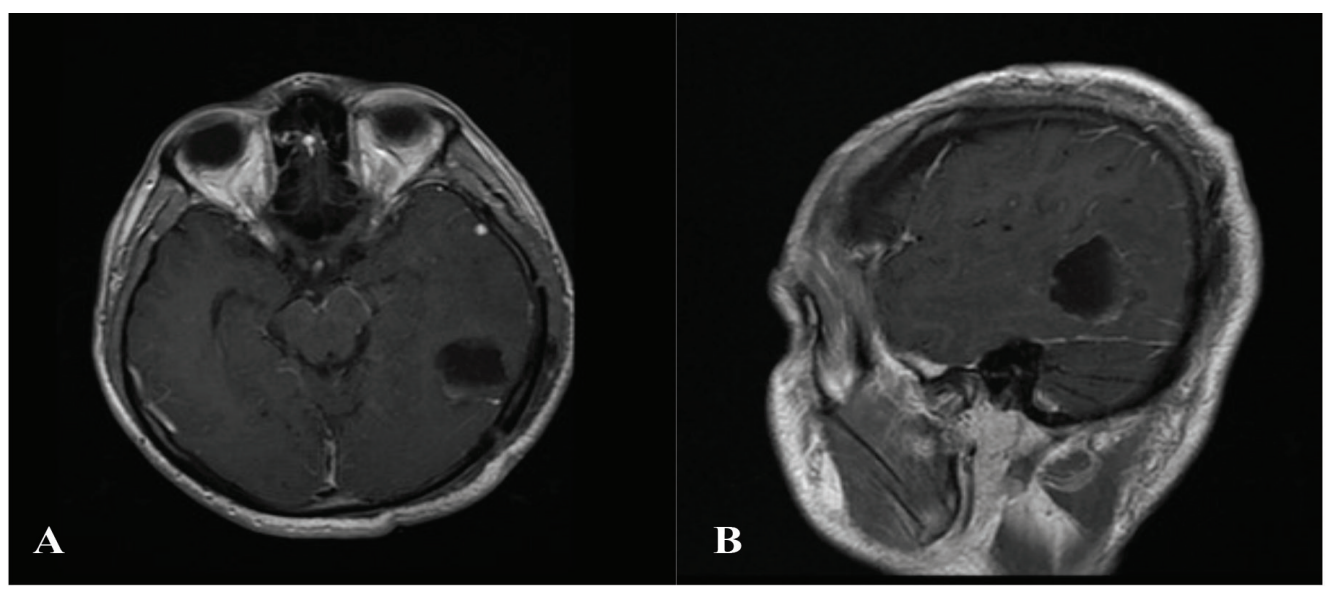

Figure 3: Early postoperative contrast-enhanced T1-weighted MRI images, one day after the operation. A: Axial plane. B: Sagittal plane. MRI: Magnetic resonance imaging

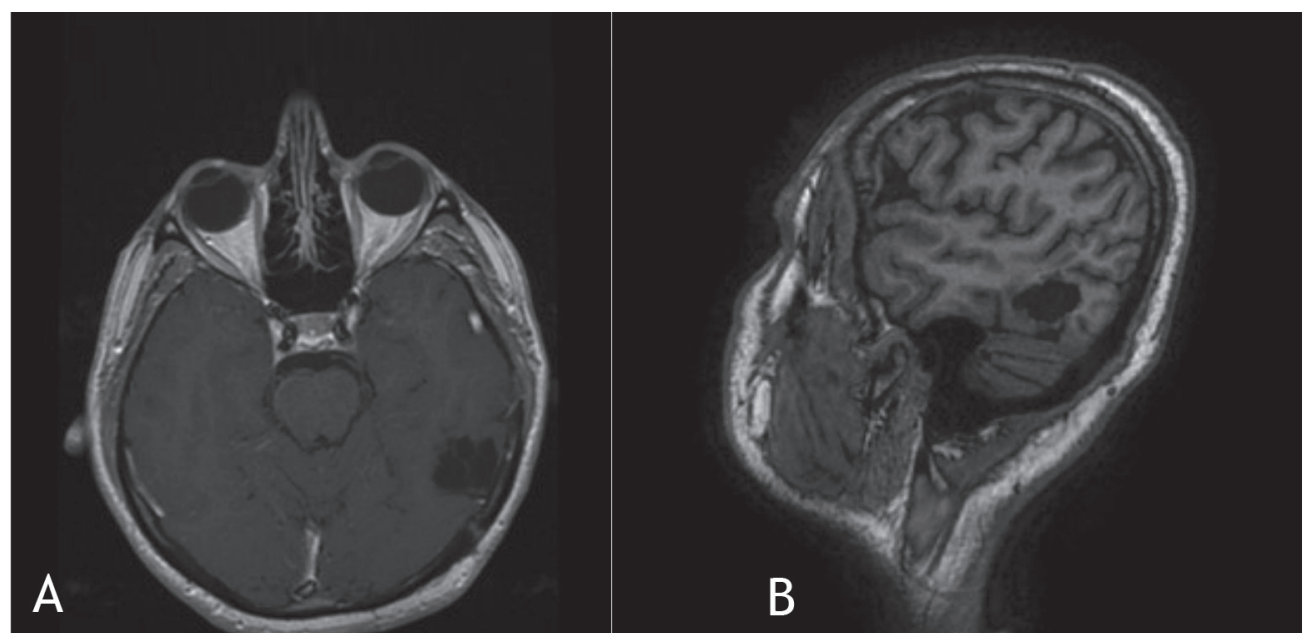

Figure 4: Late postoperative contrast-enhanced T1-weighted MRI images, approximately three and a half years after the operation. A: Axial plane. B: Sagittal plane.

MRI: Magnetic resonance imaging 

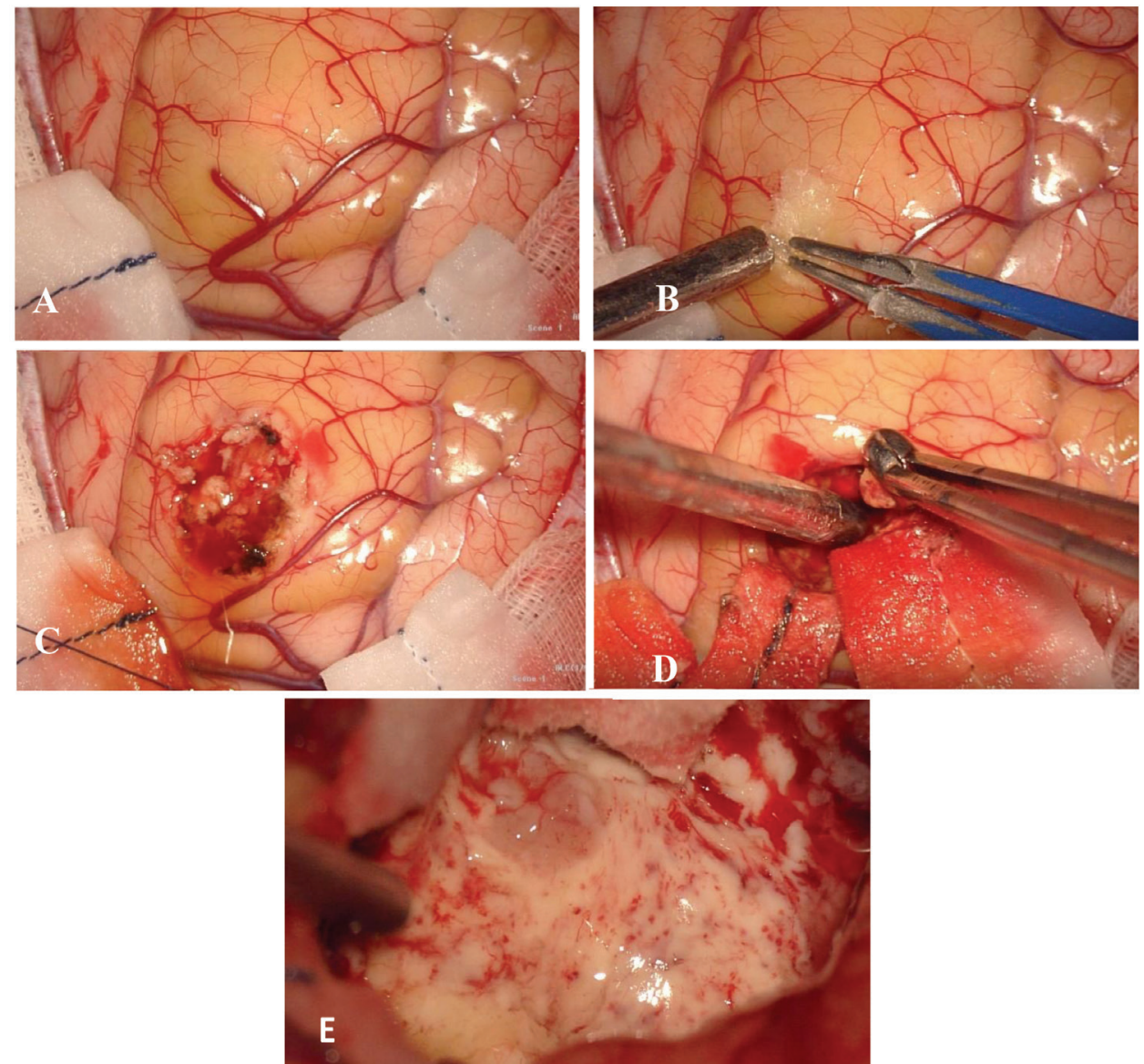

Figure 5: A-E: Perioperative images.
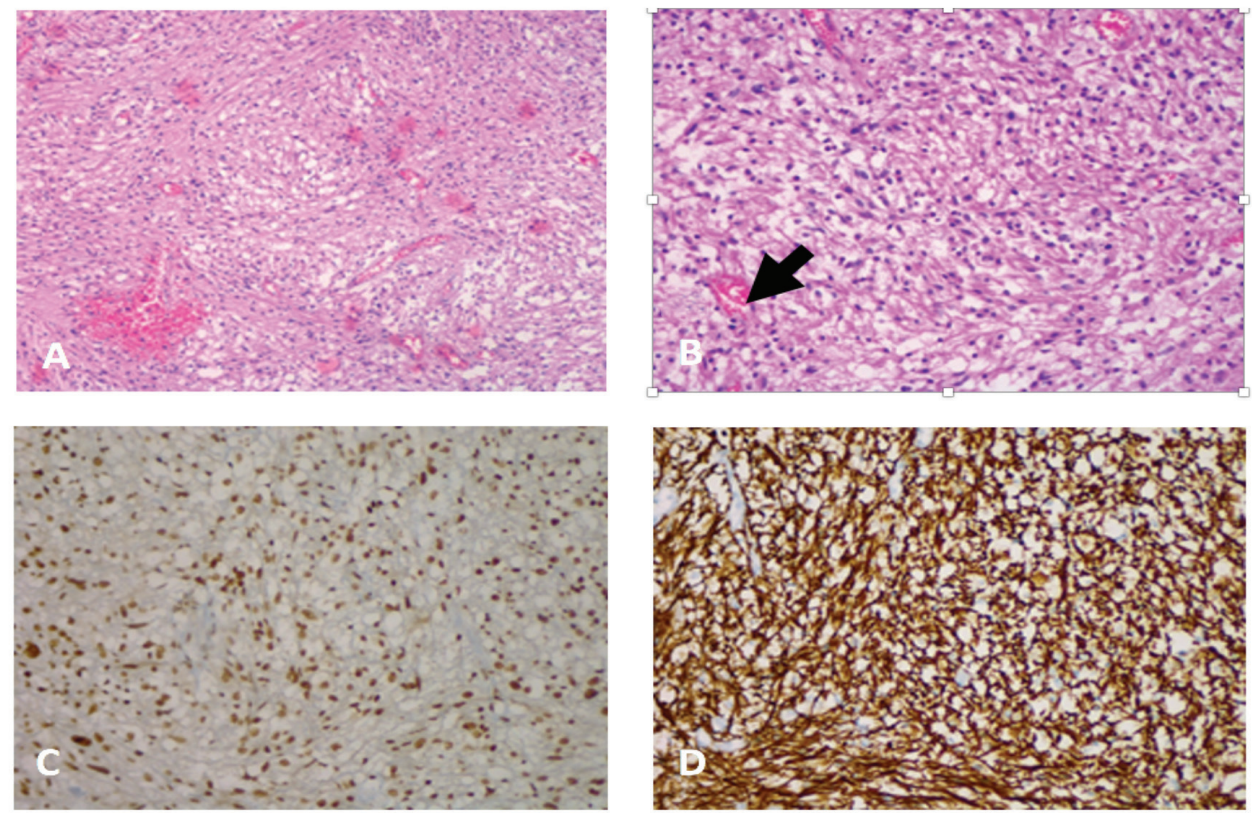

Figure 6: A: Small microcystic cavities and glial tumors containing increased vascular structures of different calibers (hematoxylin \& eosin stain, x100 magnification). B: The neoplastic glial cells, pilocytic cells with long thin nuclei, protruding cytoplasms, and Rosenthal fiber which is shown with an arrow (hematoxylin \& eosin stain, x200 magnification). C: Tumor diffuse nuclear reaction with ATRX (immunoperoxidase, x200 magnification). D: Diffuse cytoplasmic and fibrillary staining with GFAP (immunoperoxidase, x200 magnification). 
There are various options for PA treatment such as subtotal resection, gross total resection, radiotherapy, adjuvant radiotherapy, and stereotactic radiosurgery (7). A gross-total resection is recommended whenever possible, as it has the best prognosis for this disease (12). PA is relatively rare in adults and is considered a potentially treatable glioma with gross total resection (15-17).

We presented a 35-year-old male patient with left temporoparietal PA with cystic and hemorrhagic components. A gross-total excision was performed, and the follow-up was uneventful. The patient had no complaints, and no radiological recurrence was present at the 3.5-year follow-up.

A typical PA is seen in pediatric patients in the cerebellum with cystic components. However, it can also be seen in adults, in cerebral hemispheres with cystic and hemorrhagic components, as in this case. The prognosis is favorable after surgical resection. Therefore, a gross-total resection followed by a close follow-up is the treatment of choice.

\section{Ethics Committee Approval: N/A}

Informed Consent: Informed verbal consent was obtained from the patient for this study.

Conflict of Interest: The authors declared no conflict of interest.

Author Contributions: Concept: Ö.P., N.C., A.E.Ç., E.M.D., B.C., A.T.A., Design: Ö.P., N.C., A.E.Ç., E.M.D., B.C., A.T.A., Supervision: Ö.P., N.C., A.E.Ç., E.M.D., B.C., A.T.A., Data Collection and/or Processing: Ö.P., N.C., A.E.Ç., E.M.D., B.C., A.T.A., Analysis and/or Interpretation: Ö.P., N.C., A.E.Ç., E.M.D., B.C., A.T.A., Literature Search: Ö.P., N.C., A.E.Ç., E.M.D., B.C., A.T.A., Writing Manuscript: Ö.P., N.C., A.E.Ç., E.M.D., B.C., A.T.A., Critical Review: Ö.P., N.C., A.E.Ç., E.M.D., B.C., A.T.A.

Financial Disclosure: The authors declared that this study received no financial support.

\section{REFERENCES}

1. Clark GB, Henry JM, McKeever PE. Cerebral pilocytic astrocytoma. Cancer 1985;56:1128-33. [Crossref]

2. Collins VP, Jones DT, Giannini C. Pilocytic astrocytoma: pathology, molecular mechanisms and markers. Acta Neuropathol 2015;129:77588. [Crossref]
3. Dirven CM, Mooij JJ, Molenaar WM. Cerebellar pilocytic astrocytoma: a treatment protocol based upon analysis of 73 cases and a review of the literature. Childs Nerv Syst 1997;13:17-23. [Crossref]

4. Üçler $N$, Ateş $T$, Sarı $M$ et al. Baş ağrısı ve nöbet şikayetiyle başvuran hastada temporal yerleşimli kalsifiye pilositik astrositom. ADYÜ Sağlık Bilimleri Derg 2015;1:122-5. [Crossref]

5. Ostrom QT, Gittleman H, Liao P et al. CBTRUS statistical report: primary brain and central nervous system tumors diagnosed in the United States in 2007-2011. Neuro Oncol 2014;16 Suppl 4:iv1-63. [Crossref]

6. Tabash MA. Characteristics, survival and incidence rates and trends of pilocytic astrocytoma in children in the United States; SEER-based analysis. J Neurol Sci 2019;400:148-52. [Crossref]

7. Bond KM, Hughes JD, Porter AL et al. Adult Pilocytic Astrocytoma: An Institutional Series and Systematic Literature Review for Extent of Resection and Recurrence. World Neurosurg 2018;110:276-83. [Crossref]

8. Mair MJ, Wöhrer A, Furtner J et al. Clinical characteristics and prognostic factors of adult patients with pilocytic astrocytoma. J Neurooncol 2020;148:187-98. [Crossref]

9. Shibao $\mathrm{S}$, Kimura $\mathrm{T}$, Sasaki $\mathrm{H}$ et al. Hemorrhagic onset of cerebellar pilocytic astrocytoma in an adult: a case report and review of the literature implying a possible relation of degenerative vascular changes to the massive intratumoral hemorrhage. Brain Tumor Pathol 2012;29:96-102. [Crossref]

10. Prasad GL, Nandeesh BN, Menon GR. Hemorrhagic presentation of intracranial pilocytic astrocytomas: literature review. Neurosurg Rev 2019;42:97-106. [Crossref]

11. White JB, Piepgras DG, Scheithauer BW et al. Rate of spontaneous hemorrhage in histologically proven cases of pilocytic astrocytoma. J Neurosurg 2008;108:223-6. [Crossref]

12. Eroes CA, Zausinger S, Kreth FW et al. Intramedullary low grade astrocytoma and ependymoma. Surgical results and predicting factors for clinical outcome. Acta Neurochir (Wien) 2010;152:611-8. [Crossref]

13. Ohgaki H, Kleihues P. Population-based studies on incidence, survival rates, and genetic alterations in astrocytic and oligodendroglial gliomas. J Neuropathol Exp Neurol 2005;64:479-89. [Crossref]

14. Louis DN, Perry A, Reifenberger G et al. The 2016 World Health Organization Classification of Tumors of the Central Nervous System: a summary. Acta Neuropathol 2016;131:803-20. [Crossref]

15. Murphy ES, Parsai S, Kano $\mathrm{H}$ et al. Outcomes of stereotactic radiosurgery for pilocytic astrocytoma: an international multiinstitutional study. J Neurosurg 2019:1-9. [Crossref]

16. Beni-Adani L, Gomori M, Spektor S et al. Cyst wall enhancement in pilocytic astrocytoma: neoplastic or reactive phenomena. Pediatr Neurosurg 2000;32:234-9. [Crossref]

17. Mayer SA, Marshall RS. On call neurology. Neurooncology. Oxford: Elsevier; 2020.p.358-77. [Crossref] 